\title{
Professional development of in-training museum educators: an experience of curriculum improvement in time of a pandemic
}

\author{
Antonella Poce ${ }^{1}$, Mara Valente ${ }^{2}$, Maria Rosaria Re $^{2}$, Francesca Amenduni ${ }^{2}$, Carlo De \\ Medio $^{2}$ \\ ${ }^{1}$ Department of Education and Humanities, University of Modena and Reggio Emilia, Italy, \\ ${ }^{2}$ Department of Education, University of Roma Tre, Italy.
}

\begin{abstract}
The present paper aims to illustrate the reorganization of two post-graduate courses, "Museum Education. Theoretical aspects" and "Advanced Studies in Museum Education" promoted by CDM (Center for Museum Studies) - Dept. of Education at Roma Tre University, carried out during the Covid-19 pandemic, and to analyze the education strategies adopted in terms of museum professionals development to face the Covid-19 museum and universities 2020 Italian lockdown.

The results emerging from the quantitative evaluation of the module "Museum and Social Networks", taking into consideration the activities and digital tools proposed, show the efficacy of the courses reorganization, in terms of transverse and professional skills development in university students, critical thinking and collaboration in particular. Moreover, the data analysis give useful indications in term of university online lectures, laboratory activities and practices in e-learning mode, evaluation tools and methodologies aimed at solliciting professional development of in-training museum educators in university learning context.
\end{abstract}

Keywords: Museum education; e-learning; evaluation; transverse skills, professional skills, emergency remote education. 


\section{Introduction}

The Creative Industries Education context, meant as museums, galleries and libraries, presents a low emphasis on the use of new digital technologies, entrepreneurship promotion, digital abilities and transverse skills development (Poce, 2019; European Commission, 2017). Both newly graduates and existing employees, especially adult professionals, in fact, lack relevant skills (OECD, 2018) for their future careers, thus having less opportunities to improve their development and to add new forms of digital expression to their work (European Commission, 2018). However, the use of web, mobile, social and analytical tools are becoming more and more popular in the field of Cultural and Creative industries, especially during the last year (NEMO, 2020). These communication channels proved to be essential for cultural institutions in general and museums in particular to face the challenges posed by the current world-wide health emergency. In a report published on the EUR LEX website the need for stronger partnerships between the cultural and creative sectors, social partners and education and training providers, both through initial training and continuing professional development was highlighted. Such closer connection should provide sectors with the mix of skills needed for creative entrepreneurship in a rapidly changing environment.

\section{The research context}

In the light of the above assumptions, CDM (Center for Museum Studies) - Dept. of Education at Roma Tre University has designed and offered a revised version of two postgraduate courses devoted to professional development of future Museum Educators named 1. Museum Education. Theoretical aspects (since 1994) 2. Advanced Studies in Museum Education ${ }^{1}$ (since 2012) offered in a blended mode (face to face - $\mathrm{f} 2 \mathrm{f}$ - and on line) on a devoted platform.

The annual II level course in "Museum Education Theoretical aspects", mostly online, allows the acquisition of the annual post-graduate course certificate. Participants learn the theoretical foundations and the practical tools for analysing museum visitors' characteristics and needs. Online activities are offered and organized into theoretical and multimedia learning units, self-assessment and educational support from tutors.

The biennial course "Advanced Studies in Museum Education" is addressed to those interested in deepening museum education theoretical framework and wish to employ educational research methods in such a context: analysing various categories of visitors' needs, training on museum standards in education, according to the latest world research results in the field. The course guarantees an international dimension to all its initiatives.

\footnotetext{
${ }^{1} \mathrm{http}: / /$ centrodidatticamuseale.it/en/post-graduate-courses-2/
} 
Lecturers expert in museum education teach $\mathrm{f} 2 \mathrm{f}$ classrooms (UCL, Loughborough Univ., National Gallery - UK; Sorbonne - Fr; Universidade Abierta - P; Smithsonian - USA). An academic year involved about 294 classroom hours, 217 distance-learning hours to carry out within a Learning Management System (LMS) named orbisdictus, 206 internship and project work hours, 33 hours of guided visits and 750 hours of study. For distance learning, online activities were divided into theoretical and multimedia learning units, with assessments and educational support from teachers. Internship activities took place at the partner companies (e.g. CoopCulture) or at public or private museums in Italy and abroad (Poce \& Iovine, 2015).

\subsection{Re-designing post-graduate courses at the beginning of the pandemic}

From the beginning of March 2020, the spread of COVID-19 imposed an immediate reorganization of the CDM post graduate courses. Even before the emergency, the postgraduate courses were intended to promote students' digital, transverse and entrepreneurship skills. The mobilization of the world of culture - in particular of the world of cultural heritage - further encouraged the post graduate courses' managing staff to create specific online teaching units aimed at understanding the current state of heritage institutions and at figuring out which could have been effective online educational activities for heritage institutions going massively online. The implementation and adaptation of the course contents were carried out together with the readjustment of the LMS activites normally employed for distance learning.

The LMS was re-arranged to host a new section entirely devoted to "extra" activities planned to deal with the emergency.

Materials shared in the Orbis Dictus LMS are Open Educational Resources (OERs), wich includes PDF file, streaming videos, apps, podcasts, assessment tests, quiz, etc. available to students and periodically updated in the e-learning platform.

A section of the e-learning platform has been reserved to the video-updates where students are periodically informed about the development of the activities and how to proceed in the course accomplishment. As far as $\mathrm{f} 2 \mathrm{f}$ teaching and learning is concerned, national and international experts and teachers involved in the post-graduate courses training activities agreed in redesigning conventional lectures and adapt them to the new digital educational context, meeting the challenge and collaborating to the outline renovated online programs.

Students interested in attending one of the modules proposed by the experts were involved according to the following model: introduction of the activity, presentation of the issue, description of the task, live sessions where the topic is discussed and elaborated. Students were in fact invited to join a virtual classroom on Microsoft Teams $\subseteq$, participating in live 
sessions where group discussions, performing tasks, group activities and presentations were delivered.

\subsection{The educational activity: Museum and Social Networks}

Within the new educational proposal offered to students, a particular attention has been paid to the analysis of the strategies adopted by museum institutions from all over the world to face the COVID-19 lockdown. Students were invited to devise project hypotheses and solutions starting from a number of case studies identified by the tutors. This can be realised through the ideation of original activities designed by considering the specific target needs and the most suitable mediation tool. Although currently visitors cannot access to the museum buildings, our students, as future museum educators, are invited to reflect upon creative opportunities to keep visitors exploring the museums' exhibition, also university ones, living an authentic experience and learning through the works of art.

The educational activity was named "Museums and Social Networks" and it wasstructured to achieve two main goals:

1. Developing analytical skills (Facione, 1990): Analysing the online presence of one or more museum institutions; Analysing its or their presence on social media; Analysing engagement strategies for facing the COVID-19 emergency carried out by the selected museum/s.

2. Developing the ability to find new solutions for the identified problems (Poce, 2017);

The second goal will be achieved by asking students to design an online educational activity, by considering the potential of specific museum's collections and resources. Students are invited to contextualise the activity at the light of the current cultural-historical context.

These activities are thought to be relevant not only to develop technical skills and abilities for future museum educators but also transverse and digital skills. Furthermore, an improvement of students' critical thinking ability on the proposed topics is expected (as identified by Facione, 1990 and Poce 2017), as well as individual and group communication, collaboration and problem solving, in order to solve those questions in a creative way.

\section{Research questions, data collection and data analysis}

Our research is aimed at understanding how the above mentioned activities could encourage the 4C skills development, including teamwork and cooperation, creativity, critical thinking, and communication among students. 
The post-graduate managing staff of the courses and the lecturers involved in the learning activities have designed an evaluation plan of the objectives achieved by the participating students, as follows:

- Formative assessment activities: during the course, two evaluation tools are used to monitor the level of knowledge acquisition and transversal skills development: a self-assessment survey (Poce, Agrusti \& Re, 2015) of the skills developed, filled in by the students at the end of the teaching module, and a closed-ended assessment test to assess the levels of knowledge acquired.

- Summative assessment / academic performance: students are asked to produce an empirical research project in the field of museum mediation, education and cultural heritage fruition. The empirical product was assessed by a group of lecturers and tutors of the course through the use of a critical thinking evaluation rubric, already used and validated in previous research in the field (Poce, 2017).

- Course assessment:final evaluation survey of the course will be filled in by the students in order to evaluate the general course progress, the specific educational activities, the tools and teaching methodologies used.

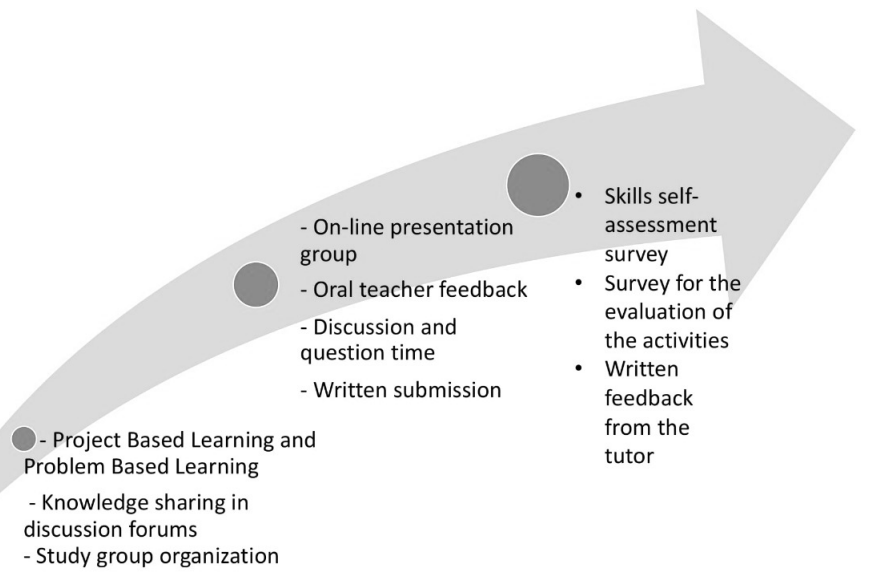

Figure 1. Monitoring, formative and summative assessment activities within the post-graduate courses.

\section{Results from "Museum and Social Network" educational activity}

The students who took part in Museum and Social Network (M\&SN) module were 12, attending both Post-graduate courses. As regards the evaluation data, the average scores expressed, considering a score scale from 1 to 5 , are well over 4 out of 5, both with regard to the qualitative aspects inherent to the contents of the activity and to the self-assessment of 
the acquired knowledge. With regard to the skills encouraged and in particular focusing attention on the $4 \mathrm{C}$ skills, the one that showed the greatest increase, according to the students, was the communication skills, probably due to the primary purpose for which the activity was designed, i.e. to be able to "communicate" the activity they designed taking as a reference the museum if selected, in times of pandemic, in an innovative, impactful and above all attractive way using social networks as a medium, in order to reach immediately the target chosen for the proposal

Relevant scores were also attributed to the development of critical thinking skills and creativity. Among the four competences the one that received a lower score than the others, but still sufficient (3.4 out of 5), was the collaboration competence. This result can be associated with the fact that, compared to the other activities proposed, the latter was the one that preferred individual rather than collaborative work.

Concerning the course assessment, the average score was 4.7 out of 5 . This result is particularly relevant if we consider the historical-cultural period of great social, political, psychological and intimate upheavals that each of us had to face.

Concerning the assessment of digital technologies, students provided the highest scores in the following areas:1) supporting for their motivation and involvement, 2) acquiring higher confidence with the use of digital technologies 3) using new e-learning platforms for the activity.

Concerning the assessment of academic learning outcomes, the students' projects have been evaluated using the CT grid (Poce, 2017) which gives scores on a scale from 1 to 5 taking into consideration the following macro-indicators: use of language, justification/argument, relevance, critical evaluation, innovation (Figure 2).

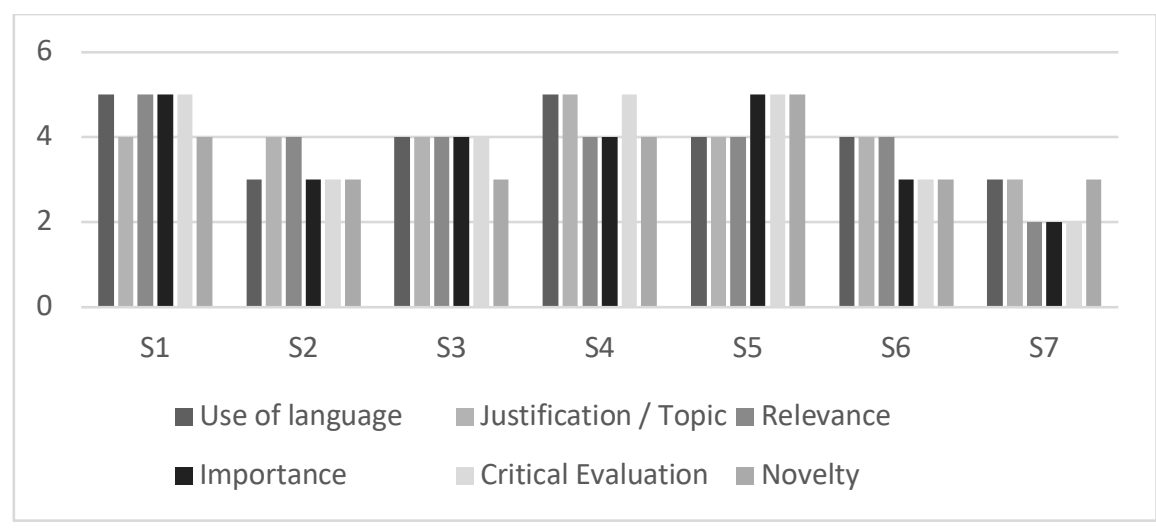

Figure 2. Evaluation of Critical Thinking in the works produced by students for the activity Museums and social networks. 
Starting from the analysis of the average results that emerged from the works, in particular from the "use of language" in which the appropriate use of punctuation, spelling, morphosyntax, lexical property is evaluated, with particular reference to the use of the technical-scientific language adopted in the empirical research in the pedagogical field, a score of 4 out of 5 was recorded. As regards the second macro-indicator "justification/argument", the average score of the papers was again 4 out of 5 , since most of the arguments turned out to be very clear and consistent. Regarding the third macro-indicator "relevance", the average scores showed a development of the projects in most cases correct and complete. Only in one case the development was assessed as partial. The average results for this indicator were 3.9 out of 5 points in total. As far as the fourth macro-indicator "importance", only one paper showed a superficial treatment. The average result was $3.7 \mathrm{pt}$ out of 5 .

The fifth macro-indicator "critical assessment" evaluates the critical re-elaboration of documents and sources (study texts, other sources mentioned) used by students to complete the assigned task. In this case the re-elaborations were mostly extensive and adequate, recording an average score of 3.9 out of 5 .

The last macro-indicator "novelty" assesses the possible presence of additional information, new ideas or solutions that students have reached after the first phase of theoretical study, indepth study and practical proposals for implementation. For the most part, correct ideas have been provided and in some cases the proposals have turned out to be original and perfectly in line with recent research in the field. The average results are 3.6 out of a total of 5 .

\section{Discussion and conclusive remarks}

The present research has shown how, thanks to the critical use of technological and digital supports, an effective way to reorganize entirely the activities of 2 post-graduate courses, which normally included f $2 \mathrm{f}$ lectures, laboratory activities and workshops at the museum. This was possible by exploiting the huge amount of digital resources offered by museums and, in the specific case, by university museums.

In the projects submitted at the end of the Museums and Social Networks activity, students often referred to digital sources and resources belonging to university museums. Given the very encouraging overall results, especially if we take into consideration the evaluations given by the students themselves, it is possible to rethink in an almost definitive way a reorganization that foresees at the same time a double possibility of using the courses, in presence and at a distance, a modality that we plan to experiment concretely next autumn. Surely, it is necessary to review in a timely manner the possibility of increasing the number of laboratory activities in e-learning mode, which has proved to be the most requested by the students and at the same time to encourage critical reflection activities with project proposals 
that refer to concrete and current scenarios to be submitted periodically to the students, preferring group research, so as to further stimulate the skills of collaboration, entrepreneurial spirit and problem solving that are among those that, in the opinion of the students themselves, should be strengthened.

\section{Authors' contributions}

A. Poce coordinated the research presented in this paper. The research group is composed by the authors of the edited contribution, in the following order: A. Poce (1, 2, 5), M. Valente (2.1) M. R. Re (4), F. Amenduni (3), C. De Medio (2.2).

\section{References}

European Commission. (2017). Europe's Digital Progress Report EDPR 2017. Available at $<$ https://ec.europa.eu/digital-single-market/en/news/europes-digital-progress-report$2017>$ (last accessed 05/08/2019).

European Commission. (2018). Digital Education Action Plan. Available at $<$ https://eurlex.europa.eu/legal-content/EN/TXT/?uri=COM:2018:22:FIN $>$ (last accessed 05/08/2019).

Facione, P. (1990). Critical thinking: A statement of expert consensus for purposes of educational assessment and instruction (The Delphi Report).

Falk, J. H., Heimlich, J., \& Bronnenkant, K. (2008). Using identity-related visit motivations as a tool for understanding adult zoo and aquarium visitors' meaning-making. Curator: The Museum Journal, 51(1), 55-79.

NEMO. (2020). Survey on the impact of the COVID-19 situation on museums in Europe Final Report. Retrived from https:/www.nemo.org/fileadmin/Dateien/public/NEMO_documents/NEMO_COVID19_Report_12.05. 2020.pdf

Not, E., \& Petrelli, D. (2018). Blending customisation, context-awareness and adaptivity for personalised tangible interaction in cultural heritage. International Journal of HumanComputer Studies, 114, 3-19

OECD. (2018). Education at a Glance: OECD Indicators. Paris: OECD Publishing.

Poce, A. (2017). Verba Sequentur. Pensiero e scrittura per uno sviluppo critico delle competenze nella scuola secondaria. Milano: Franco Angeli.

Poce, A. (2019). Information and data literacy skills development in Creative Industries Adult Education: the Digiculture project. PEDAGOGIA OGGI, 17(2), 184-201.

Poce, A., \& Iovine, A. (2015). From cultural to socio-economic capital: lessons from a postgraduate course in 'standards for museum education'. Engaging the Senses: ObjectBased Learning in Higher Education, 177.

Poce, A., Agrusti, F., \& Re, M. R. (2015). Sviluppo di uno strumento di valutazione delle risorse aperte (Oers). CADMO. 